25. Саксонов С.В. О видах растений, лишайников и грибов Красной книги Российской Федерации // Самарская Лука: Бюллетень. 2006. № 17. С. 253-285.

26. Соловьёва В.В., Старкова Т.С., Старков М.Н. Популяции редких охраняемых растений на склонах Шаронова оврага Красноярского района // Природное наследие России: изучение, мониторинг, охрана: Материалы Международной конф. (Тольятти, Россия, 21-24 сентября 2004 г.). Тольятти: ИЭВБ РАН, 2004. C. 256.

27. Ужамецкая Е.А. Растительные ассоциации балки Каменный дол, рекомендуемые к охране // Природное наследие России: изучение, мониторинг, охрана: Материалы Междунар. конф. (Тольятти, Россия, 21-24 сентября 2004 г.). Тольятти: ИЭВБ РАН, 2004. C. $327-328$.

28. Флора Нижнего Поволжья. Т. 1 Споровые, голосеменные, однодольные. М.: Товарищество научных изданий КМК, 2006. С. 363.

29. Флора памятника природы «Гора Зелёная» Елховского района Самарской области / С.В. Саксо- нов, А.В. Лобанова, А.И. Иванова, В.Н. Ильина и др. // Вестник Волжского университета им. В.Н. Татищева. Серия «Экология». Вып. 5. Тольятти: ВУиТ, 2005. C. 6-20.

30. Флора Сибири. Т. 4. Новосибирск: Наука, 1987. C. 101.

31. Изучение лесных экосистем степного Поволжья / Н.М. Матвеев, В.Г. Терентьев, К.Н. Филиппова, О.Е. Дёмина. Куйбышев: Куйбышевский госуниверситет, 1990. С. 48.

32. Флористическое разнообразие особо ценного Красносамарского лесного массива Самарской области: I. Сосудистые растения // Самарская Лука: проблемы региональной и глобальной экологии. 2010. T. 19, № 1. C. 111-136.

33. Матвеев Н.М., Филиппова К.Н., Дёмина О.Е. Систематический и экоморфный анализ флоры Красносамарского лесного массива в зоне настоящих степей // Вопросы экологии и охраны природы в лесостепной и степной зонах: Межв. сб. науч. тр. Самара: Самарский университет, 1995. С. 41-71.

\title{
PRELIMINARY RESULTS OF THE MONITORING BIO-ECOLOGICAL FEATURES OF PLANTS FRITILLARIA RUTHENICA WIKSTR. IN THE MODEL FOREST HABITATS OF THE KRASNOSAMARSKY FOREST
}

(C) 2016

\section{M.G. Kotelnikova, postgraduate student of the Chair of Ecology, Botany and Nature Protection} Samara National Research University, Samara (Russia)

Abstract. The article presents some preliminary results of the monitoring of Fritillaria ruthenica Wikstr. plants (category of rare and endangered plant species, included in the Red Books of Russia and Samara Region). By summarizing the available sources of science literature we have compiled a general description of morphological and bioecological species characteristics. The results of the field study fulfilled in 2012-2014 in Krasnosamarsky forestry (Samara region) were used to determine morphometric parameters of Fritillaria ruthenica plants. The data also helped us to assess the variability level and to make a comparison with plant quantitative traits given in the literature. It was found that the shoot length of Fritillaria ruthenica plants from model biotope in Krasnosamarsky forest in 2012-2014 varied in the range of $20 \ldots 70 \mathrm{~cm}$, in 2012 and 2013 individuals with long shoots about $50 \mathrm{~cm}$ dominated, in 2014 with shoot length about 50 and $60 \mathrm{~cm}$. The feature of the shoot length is characterized by plasticity, the highest level of variation was observed in 2013. The lengths of shoots are inside the range specified for the various parts of the area in the literature with a significant proportion of "tall" plants in the studied population. This may be a sign of good growth conditions for Fritillaria ruthenica that gives an opportunity to the plant conservation in natural communities in the absence of limited anthropogenic factors.

Keywords: Fritillaria ruthenica Wikstr; morphological and bioecological features; quantitative and qualitative characteristics; shoot length; Krasnosamarsky forest; model biotope; Samara region.

\section{ОСОБЕННОСТИ ПИЩЕВОГО ПОВЕДЕНИЯ ЕНОТОВИДНОЙ СОБАКИ (NYCTEREUTES PROCYONOIDES GRAY, 1834) В ЗАВИСИМОСТИ ОТ ВЕЛИЧИНЫ СНЕЖНОГО ПОКРОВА} НА ПОЙМЕННОЙ ТЕРРИТОРИИ НАЦИОНАЛЬНОГО ПАРКА «САМАРСКАЯ ЛУКА» (C) 2016

В.В. Мартынова, аспирант кафедры экологии, ботаники и охраны природы Самарский национальный исследовательский университет имени академика С.П. Королёва, Самара (Россия)

Аннотащия. Енотовидная собака в пределах Самарской Луки является интродуцированным видом, отличается большой экологической пластичностью. Она успешно акклиматизировалась, и в настоящий момент продолжает расширять свой ареал. В этом аспекте особенно актуальным является изучение поведения вида. Важно отметить адаптацию вида в условиях антропогенной нагрузки, которая присутствует в условиях национального парка. Исследования проводилось на пойменных территориях национального парка Самарская Лука (с. Мордово и с. Малая Рязань), так как енотовидная собака тяготеет к пойменным участкам рек, островам и протокам, и сравнительно редко появляется на больших открытых пространствах. Объект исследования является популяция енотовидных собак пойменной территории национального парка. Был использован метод де- 
тальных троплений зимних следов животных. В статье приводятся данные о суровости погодных условий, расчет индекса Бодмана для территорий тропления в период исследования. Приведены данные сравнения материалов зимних троплений в многоснежный (2012 г.) и малоснежный (2013 г.) периоды. Полученные данные иллюстрируют различия в поведенческой (исследовательской, пищевой и поисково-пищевой) активности самцов и самок енотовидной собаки в зависимости от величины снежного покрова и погодных условий. Результат согласуется с имеющимися в литературе сведениями о суровости климата в Самарском регионе и изменением поведения псовых в разные сезоны. Полученные данные могут быть использованы в работе сотрудников особо охраняемых природных территорий, лесохозяйственных и охотничьих организаций для популяционного мониторинга вида-интродуцента.

Ключевые слова: енотовидная собака; Nyctereutes procyonoides; интродуцент; псовые; пищевое поведение; поисково-пищевое поведение; поведенческая активность; антропогенный пресс; адаптация; снежный покров; коэффициент Бодмана; особо охраняемые природные территории; Самарская область; пойменные территории.

Попытки интродукции енотовидной собаки предпринимались в Самарской области дважды (в 1934 и 1955 гг.), однако завезенные хищники не смогли закрепиться на новой территории, и уже в 60-х гг. об их встречах в Самарской области сведений не обнаружено [1]. На территории национального парка «Самарская Лука» вид был отмечен уже в 80-е гг. $\mathrm{XX}$ века, а в настоящее время он широко распространен на пойменных территориях области [2; 3, 4]. В литературе отмечена всеядность и слабое развитие хищничества у енотовидной собаки [5], при этом она выступает как самый широкий эврифаг и самый растительноядный вид своего семейства. В ее рационе присутствуют мышевидные грызуны, птицы и их яйца, насекомые, моллюски, ракообразные, рептилии и амфибии, ягоды и опавшие плоды, падаль, отбросы, рыба $[6 ; 7,8]$. Ряд исследователей отмечают негативное влияние енотовидной собаки на численность охотничье-промысловых птиц $[9 ; 10,11]$. Другие авторы считают, что вред ее в охотничьих хозяйствах преувеличен [7], и скорее характеризуют присутствие вида-полифага как положительное (учитывая уничтожение этим хищником вредителей сельского и лесного хозяйства) $[12 ; 13]$. В литературе почти нет сведений об исследовании пищевого поведения видаинтродуцента, который сейчас широко распространен в национальном парке и уже стал полноправной частью его экосистем [14], поэтому особенно важным становится его изучение как отражения одного из аспектов его влияния на аборигенные виды особо охраняемых природных территорий. Целью работы было изучение пищевого поведения енотовидной собаки в сезоны с различной снежностью. Были поставлены задачи проанализировать особенности поведения енотовидной собаки в сезоны с различной снежностью, отметить полоспецифические различия в пищевом поведении, выявить особенности в реакциях на объекты естественной среды и антропогенного характера.

Территория исследования. Особенности пищевого поведения енотовидной собаки исследовались на примере популяции, обитающих на поймах около с. Мордово и с. Малая Рязань, так как предпочтение при расселении енотовидная собака отдает пойменным участкам рек $[15 ; 16]$.

Методы исследований. Наиболее полную картину при анализе пищевого поведения можно получить путем детальных троплений [17], нами была использована методика троплений следов животных в зимний период [18; 19, 20].

Результаты и их обсуждение. В Самарской области снежный покров наблюдается несколько месяцев в году, его толщина и структура определяет сезонную изменчивость пищевого поведения [21; 22]. При проведении экологических исследований часто требуется учет действия многих факторов среды. Мы воспользовались данными измерений ближайшей к району исследований метеостанции [23], на их основании был произведен расчет индекса суровости по формуле Г. Бодмана:

$$
\mathrm{S}=(1-0,04 \mathrm{t}) \times(1+0,272 \mathrm{~V}),
$$

где $\mathrm{S}$ - балл суровости; $\mathrm{t}$ - средняя температура воздуха, ${ }^{\circ} \mathrm{C} ; \mathrm{V}-$ средняя скорость ветра, $\mathrm{M} / \mathrm{c}$.

Средний балл суровости за 2012-2013 гг. составлял 2,10 балла для каждого из сезонов, наиболее сильно среди всех параметров отличалась высота снежного покрова (для 2013 г. он составил в среднем 40,55 cM, для 2012 г. - 70,38 cм). По полученным для недель троплений данным был построен график (рис. 1.).

В литературе зима в Самарской области характеризуется как «малосуровая» [24], основные точки полученного графика расположены в границах характерных для области значений (зоны средних широт).

Для изучения поведения енотовидной собаки ежегодно с 2009 г. проводились зимние тропления, учитывались элементарные двигательные акты, смены аллюра, остановки, пассивно-оборонительные, пищевые и поисково-пищевые, исследовательские реакции. На основании собранных материалов был сделан обсчет данных троплений за 2012 и 2013 гг. с пересчетом показателей на 100 реакций (на 100\%) [25; $26,27]$. Среди общего числа реакций енотовидной собаки было выделено количество реакций на объекты естественной среды и объекты антропогенного характера, для сравнения этих значений в сезоны с различной снежностью. Результаты представлены в таблице (табл. 1).

Было отмечено, что число локомоторных реакций возросло в многоснежный период для особей обеих половых групп, что связывается с затрудненностью локомоции и заносами дорог человека и снегоходов, которые используются енотовидными собаками [28]. В многоснежный период у самцов наблюдается увеличение показателей остановок и смен аллюра. Эти данные коррелируют с уменьшением у самцов исследовательских реакций (в том числе на объекты антропогенного происхождения), которые заменяются пассивно-оборонительными (количество этих реакций возрастает в многоснежный период и у самцов, и у самок). Хотя обычно самцы более смело ведут себя по отношению к новым объектам среды по сравнению с самками [29], у них отмечено снижение числа реакций на объекты антропогенного характера, а 
Мартынова В.В.

Особенности пищевого поведения енотовидной собаки...

03.02.00 - общая биология

увеличение общей локомоторной активности обусловлено ростом числа пассивно-оборонительных реакций. У самок отмечается рост числа исследовательских реакций на объекты естественной природы и антропогенного характера, что можно связать с увеличением интенсивности использования окружающих объектов. Увеличение показателей поисковопищевого поведения у самок в многоснежный период связано с тем, что особи проявляют больше локомоторной активности при попытке поймать добычу, при этом результативность самой охоты снижается, о чем свидетельствует снижение значений пищевых реакций (они уменьшились как у самок, так и у самцов). Важно отметить, что активное проявление поисковопищевого поведения не эквивалентно успешности охоты. У самок не отмечены поисково-пищевые и пищевые реакции на объекты антропогенного характера ни в один из сезонов троплений, но в многоснежный период возрастают поисково-пищевые на объекты естественной среды (прослеживается более интенсивное использование территории). У самцов наблюдается небольшое возрастание числа поисково-

пищевых реакций на антропогенные объекты в многоснежный период (и уменьшение этих реакций на объекты естественной среды), а в малоснежный поисково-пищевые реакции на антропогенные компоненты у самцов вовсе не отмечены. Пищедобывательное поведение, наряду с маркировочным, рассматривается как одно из наиболее энергозатратных, этим объясняется снижение числа реакций в многоснежный период. Таким образом, выявлены различия в поведенческой активности енотовидной собаки в зависимости от величины снежного покрова, прослеживаются полоспецифические особенности в поведении обеих групп исследуемых животных. Это связано как с морфологическими параметрами вида, действием факторов погоды, так и присутствием антропогенной нагрузки. Данные можно использовать для оценки степени воздействия человека на среду обитания енотовидной собаки, для исследования поведения других таксономических групп животных, т.к. способы обработки материалов позволяют сформировать детальное представление о процессах, протекающих внутри популяции.

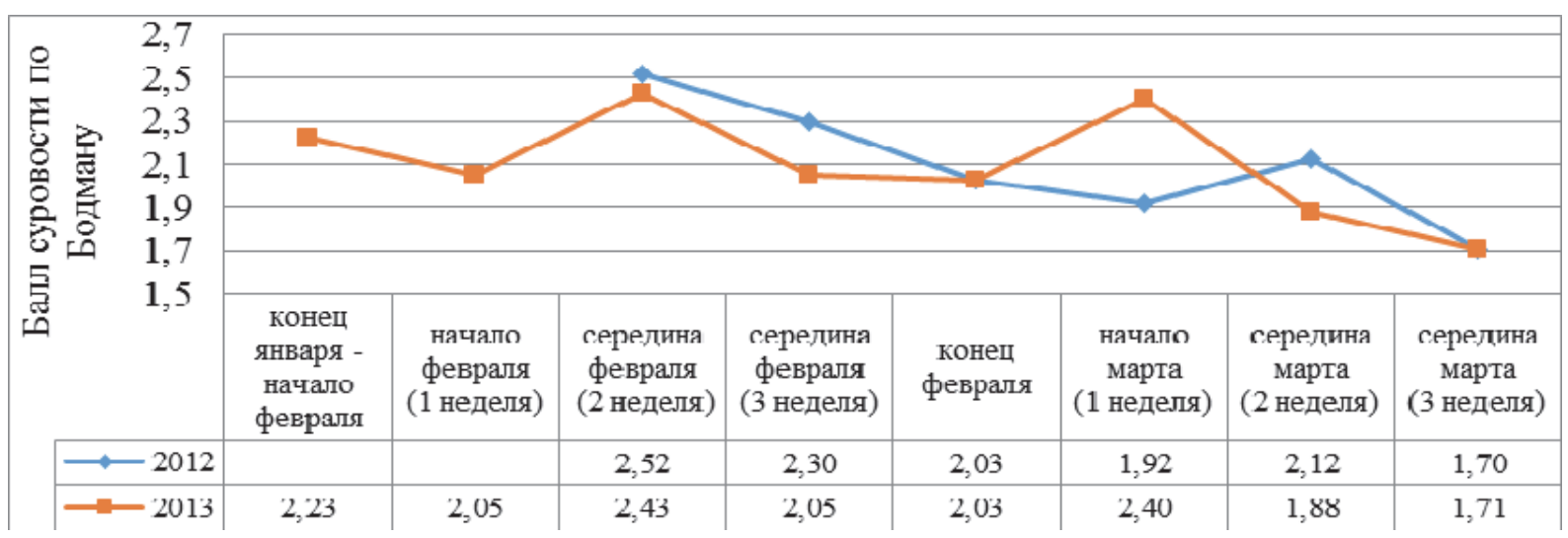

Рисунок 1 - Динамика показателя жесткости погоды в снежные периоды 2012 и 2013 гг.

Таблица 1 - Сравнительный анализ поведенческой активности енотовидной собаки и полоспецифическое соотношение реакций на объекты в расчете на 100 реакций

\begin{tabular}{|c|c|c|c|c|c|c|c|c|c|c|c|}
\hline \multirow[b]{3}{*}{$\begin{array}{l}\text { № } \\
\text { п/П }\end{array}$} & \multirow[b]{3}{*}{$\begin{array}{c}\text { Наименование ти- } \\
\text { пов реакций }\end{array}$} & \multirow[b]{3}{*}{ 官 } & \multicolumn{9}{|c|}{ Пересчет на 100 реакций (на 100\%) } \\
\hline & & & \multicolumn{2}{|c|}{$\begin{array}{c}\text { Объекты } \\
\text { естественней } \\
\text { среды }\end{array}$} & \multirow{2}{*}{ 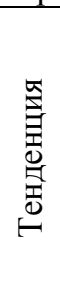 } & \multicolumn{2}{|c|}{$\begin{array}{l}\text { Объекты } \\
\text { антропогенного } \\
\text { характера }\end{array}$} & \multirow{2}{*}{ 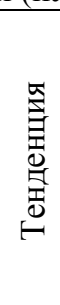 } & \multicolumn{2}{|c|}{$\begin{array}{c}\text { Все объекты } \\
\text { в сумме }\end{array}$} & \multirow{2}{*}{ 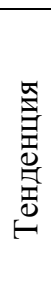 } \\
\hline & & & 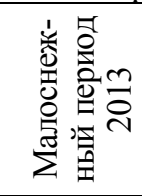 & 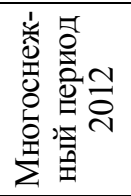 & & 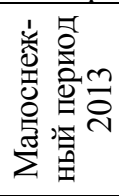 & 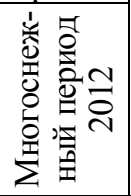 & & 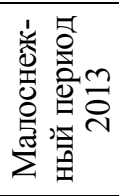 & 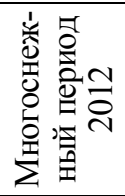 & \\
\hline \multirow{2}{*}{1} & \multirow{2}{*}{$\begin{array}{l}\text { Локомоторные ре- } \\
\text { акции }\end{array}$} & \multirow{2}{*}{$\frac{p}{i}$} & \multirow{8}{*}{\multicolumn{6}{|c|}{$\begin{array}{c}\text { Реакции отмечались вне зависимости от конкрет- } \\
\text { ного объекта (естественной природы или антро- } \\
\text { погенного характера) }\end{array}$}} & 8,24 & 10,10 & $\uparrow$ \\
\hline & & & & & & & & & 3,29 & 10,41 & $\uparrow$ \\
\hline \multirow{2}{*}{2} & \multirow{2}{*}{ Остановки } & \multirow{2}{*}{$\frac{9}{1}$} & & & & & & & 11,54 & 9,09 & $\downarrow$ \\
\hline & & & & & & & & & 5,39 & 10,41 & $\uparrow$ \\
\hline \multirow{2}{*}{3} & \multirow{2}{*}{ Смена аллюра } & q & & & & & & & 4,40 & 3,03 & $\downarrow$ \\
\hline & & $\hat{0}$ & & & & & & & 0,60 & 2,84 & $\uparrow$ \\
\hline \multirow{2}{*}{4} & \multirow{2}{*}{$\begin{array}{l}\text { Пассивно-обо- } \\
\text { ронительные }\end{array}$} & $q$ & & & & & & & 3,30 & 8,08 & $\uparrow$ \\
\hline & & $\pi$ & & & & & & & 0,90 & 0,95 & $\uparrow$ \\
\hline \multirow{2}{*}{5} & \multirow{2}{*}{$\begin{array}{l}\text { Исследователь- } \\
\text { ские реакции }\end{array}$} & $q$ & 1,65 & 5,05 & $\uparrow$ & - & 1,01 & $\uparrow$ & 1,65 & 6,06 & $\uparrow$ \\
\hline & & $\hat{\sigma}$ & 3,29 & 3,79 & $\uparrow$ & 2,40 & 0,32 & $\downarrow$ & 5,69 & 4,10 & $\downarrow$ \\
\hline \multirow{2}{*}{6} & \multirow{2}{*}{$\begin{array}{l}\text { Поисково- } \\
\text { пищевые }\end{array}$} & 9 & 8,79 & 22,22 & $\uparrow$ & - & - & $\downarrow$ & 8,79 & 22,22 & $\uparrow$ \\
\hline & & $\pi$ & 22,46 & 13,56 & $\downarrow$ & - & 0,63 & $\uparrow$ & 22,46 & 14,20 & $\downarrow$ \\
\hline \multirow{2}{*}{7} & \multirow{2}{*}{ Пищевые } & 우 & 16,48 & - & $\downarrow$ & - & - & - & 16,48 & - & $\downarrow$ \\
\hline & & $\pi$ & 11,08 & 9,15 & $\downarrow$ & - & - & - & 11,08 & 9,15 & $\downarrow$ \\
\hline
\end{tabular}

Примечание: $\uparrow$ - увеличение числа реакций по сравнению с малоснежным периодом, $\downarrow$ - уменьшение 


\section{СПИСОК ЛИТЕРАТУРЫ:}

1. Шапошников В.М. Реконструкция фауны промысловых животных в лесных биогеоценозах в пределах степной и лесостепной зон Куйбышевской области // Вопросы лесной биогеоценологии, экологии и охраны природы в степной зоне. Куйбышев: КГУ, 1977. С. 86-91.

2. Вехник В.П. Критические замечания к фаунотаксономическому составу млекопитающих Самарской Луки // Биологическое разнообразие заповедных территорий: оценка, охрана, мониторинг: Сборник научных трудов Жигулёвского государственного заповедника им. И.И. Спрыгина; Самара, 2000. С. 310 317.

3. Горелов М.С. Обзор териофауны Правобережья и Самарского Заволжья и некоторые особенности ее формирования // Самарская Лука: Бюллетень. 1991. № 1. С. $63-78$.

4. Камалова Е.С., Фокина М.Е. Освоение новой среды обитания енотовидной собакой (Nyctereutes procyonoides) и изменение значимости объектов коммуникативного характера с 1995 по 2012 гг. на примере Мордовинской поймы Национального парка «Самарская Лука» // Биологическое сигнальное поле млекопитающих. Коллективная монография. под редакцией А.А. Никольского, В.В. Рожнова. М.: Товарищество научных изданий КМК. 2013. С. 116-120.

5. Юдин В.Г. Енотовидная собака Приморья и Приамурья. М.: Наука, 1977. 161 с.

6. Кузнецов Г.В. Млекопитающие Вьетнама. М.: Товарищество научных изданий КМК, 2006. С. 128129.

7. Сизонов О.В. Енотовидная собака (Nyctereutes procyonoides Gray) плавневой зоны Восточного Приазовья: дис. ... канд. биол. наук. Ставрополь, 2006. $159 \mathrm{c}$.

8. Насимович А.А., Исаков Ю.А. Песец, лисица, енотовидная собака. М.: Наука, 1985. 159 с.

9. Бурко Л.Д., Гричик В.В. Позвоночные животные Беларуси: Учеб. пособие. Мн.: БГУ, 2003. С. 373.

10. Дулицкий А.И. Млекопитающие Крыма. Симферополь: Крымское учебно-педагогическое государственное издательство, 2001. 224 с.

11. Гудков В.М. Следы зверей и птиц. М.: Изд-во: Вече, 2007. 592 с.

12. Данилов П.И., Русаков О.С., Туманов И.Л. Хищные звери Северо-Запада СССР. Л., 1979. С. 5-25.

13. Литвинов В.П., Иванов М.В. Трофические отношения и питание енотовидной собаки в ВолгоАхтубинской пойме и низовьях дельты Волги // Териофауна России и сопредельных территорий. VII съезд Териологического общества: Материалы Международного совещания. 6-7 февраля 2003 г. М., 2003. С. 191-200.

14. Бобров В.В., Варшавский А.А., Хляп Л.А. Чужеродные виды млекопитающих в экосистемах России / ред. Ю.Ю. Дгебуадзе, В.М. Неронов. М.: Товарищество научных изданий КМК, 2008. 232 с.
15. Лавров Н.П. Итоги интродукции енотовидной собаки (Nyctereutes procyonoides Grey) в отдельные области СССР // Уч. зап. МГЗПИ. Вып. 29. М.: Просвещение, 1971. С. 101-160.

16. Волох А.М., Роженко Н.В. Биотическое распределение енотовидной собаки в степной зоне Украины // Актуальні питания збережения I відиовления степових екосистем на півдиі України. Матер. Міжнар. наук. конфер. до 100-річчя зап-ка «АсканіяНова». Аскания-Нова, 1998. С. 252-254.

17. Новиков Г.А. Полевые исследования экологии наземных позвоночных животных. М.: Советская наука, 1949. 567 с.

18. Наумов Н.П. Биологические (сигнальные) поля и их значение в жизни млекопитающих // Успехи современной териологии. М.: Наука, 1977. С. 93-108.

19. Мозговой Д.П. Информационно-знаковые поля млекопитающих: теория и практика полевых исследований: автореф. дис. ... д-ра биол. наук. Тольятти, 2005. 49 с.

20. Мозговой Д.П. Информационно-знаковые поля млекопитающих: теория и практика полевых исследований: дис. в форме научного доклада. Самара: Универс-групп, 2005. 50 с.

21. Формозов А.Н. Звери, птицы и их взаимоотношения со средой обитания. М.: Наука, 1976. C. 216-265.

22. Формозов А.Н. Снежный покров как фактор среды, его значение в жизни млекопитающих и птиц СССР. 2-е изд. М.: Изд-во МГУ, 1990. 287 с.

23. Расписание погоды [Электронный ресурс] // http://rp5.ru.

24. Исаева М.В. Пространственно-временная изменчивость основных биоклиматических показателей на территории приволжского федерального округа: автореф. дис. ... канд. геогр. наук. Казань, 2009. C. 14-22.

25. Склюев В.В. Исследование состояния популяции лисицы Красноармейского района Самарской области // Известия Самарского научного центра Российской академии наук. 2009. Т. 11. № 1(4). C. 661-665.

26. Фокина М.Е. Анализ информационно-знаковых полей енотовидной собаки (Nyctereutes procyonoides Gray) и лисицы обыкновенной (Vulpes vulpes L.) (на примере национального парка «Самарская Лука»): дис. ... канд. биол. наук. Самара, 2006. 153 с.

27. Мозговой Д.П., Розенберг Г.С., Владимирова Э.Д. Информационные поля и поведение млекопитающих: Уч. пособ. Самара: Самарский университет, 1998. 92 c.

28. Камалова Е.С., Лапузина В.В. Особенности внутривидовой коммуникации енотовидной собаки ( $N y c$ tereutes procyonoides) // Териофауна России и сопредельных территорий: Международное совещание (IX Съезд Териологического общества при РАН). М.: Товарищество научных изданий КМК, 2011. С. 195.

29. Геодакян В.А. Эволюционная теория пола // Природа, 1991. № 8. С. 60-69. 


\title{
SOME ASPECTS OF RACCOON DOG'S (NYCTEREUTES PROCYONOIDES GRAY, 1834) FOOD BEHAVIOR IN DEPEND ON DEPTH OF SNOW COVER ON THE FLOODPLAIN TERRITORY OF NATIONAL PARK «SAMARSKAYA LUKA»
} (C) 2016

\author{
V.V. Martynova, postgraduate student of the Chair of Ecology, Botany and Nature Protection \\ Samara National Research University, Samara (Russia)
}

\begin{abstract}
The raccoon dog, which is inhabit the territory of national park «Samarskaya Luka», considered an invasive species with the high ecological plasticity. It has been acclimatized successfully and still continues to expand its range. Taking into account this fact, it is particularly relevant to reveal some aspects of its behavior. The important point is the adaptation of the species in the conditions of anthropogenic press, which are observed in the national park's territory. The studies was carried out on the riparian territories of the national park «Samarskaya Luka» (village Mordovo and village Malaya Ryazan), because the raccoon dog tends to inhabit the floodplain areas, river banks, islands and channels, and avoid large open fields. The research object is the raccoon dogs' population on riparian territories of the national park. The study was carried out by detailed winter footprints tracking method. The article presents data on the weather's severity conditions, Bodman index was calculated for the areas of tracking in the study period. The data compared detailed winter tracking in the snowy (2012) and snowless (2013) research period materials are presented. The obtained data illustrate differences in research, food and food searching behavioral activity of raccoon dog's males and females depending on the depth of the snow cover and weather conditions. The results are consistent with the literature data on the weather's severity in the Samara region and changes of canids behavior's in different seasons. The data obtained can be used by staff of specially protected natural areas, forestry and hunting organizations for introduced species' population monitoring.

Keywords: raccoon dog; Nyctereutes procyonoides; introduced species; canids; food behavior; food searching behavior; behavioral activity; anthropogenic press; adaptation; snow cover; Bodman index; special protected natural areas; Samara region; floodplain areas.
\end{abstract}

УДК 579.69

\section{ВЛИЯНИЕ ТЕМПЕРАТУРЫ И ИСТОЧНИКОВ УГЛЕРОДА НА БИОСИНТЕЗ АУКСИНА ШТАММОМ RHODOCOCCUS ERYTHROPOLIS BКМ AC-2017D И ЕГО ФИТОСТИМУЛИРУЮЩАЯ АКТИВНОСТЬ В ПОЧВЕННЫХ УСЛОВИЯХ} (C) 2016

\section{Д.Н. Отрошко, аспирант кафедры генетики, микробиологии и биотехнологии}

B.B. Шеремет, магистрант биологического факультета

Н.Н. Волченко, кандидат биологических наук, доцент кафедры генетики, микробиологии и биотехнологии А.А. Худокормов, кандидат биологических наук, доцент кафедры генетики, микробиологии и биотехнологии А.А. Самков, кандидат биологических наук, преподаватель кафедры генетики, микробиологии и биотехнологии Кубанский государственный университет, Краснодар (Россия)

Аннотация. Целью исследования было изучение влияния температуры и источников углерода на способность к синтезу индолил-три-уксусной кислоты (ИУК) штамма Rhodococcus erythropolis BKM Ac-2017D на минеральной среде с добавлением в качестве предшественника триптофана в концентрации 0,5 г/л. Фитостимулирующий эффект был показан в почвенном эксперименте с применением газонной травосмеси (Festuca rubra $-30 \%$, Lolium perenne $-30 \%$, Poa pratensis $-20 \%$, Festuca rubra trichlorophylla $-15 \%$, Festuca ovina 5\%). Штамм-деструктор нефтепродуктов Rhodococcus erythropolis BKM Ac-2017D был способен к продукции фитогормона ауксина как на гексадекане, так и на сахарозе. Обнаружены различия в продукции ауксина при температурах $\left(15,25,35^{\circ} \mathrm{C}\right)$ и на разных типах углеродных субстратов. Если источником углерода выступала сахароза, то максимальная продукция фитогормона в 34,4 мкг/мл наблюдалась при температуре $15^{\circ} \mathrm{C}$. При культивировании микроорганизмов на гексадекане максимальный выход индолил-3-уксусной кислоты был отмечен при температуре $25^{\circ} \mathrm{C}$, он составил 77,69 мкг/мл. В полевом эксперименте было продемонстрировано, что максимальной фитостимулирующей активностью по отношению к газонной траве в условиях урбанозёма обладали супернатант, содержащий экзометаболиты исследуемого микроорганизма, и нативная жидкая культура - они в несколько раз увеличивали сырую фитомассу и всхожесть газонной травы относительно обработки водой и химически синтезированной ИУК.

Ключевые слова: индолил-3-уксусная кислота (ИУК); растительно-микробные взаимодействия; нефтеокисляющие бактерии; Rhodococcus erythropolis; стимулирующие рост растений бактерии (PGPB); ризосфера; всхожесть растений; фитостимуляция; ризоремедиация; экологическая микробиология и биотехнология.

В настоящее время существует тенденция к росту антропогенного влияния на экосистемы. К наиболее распространённым поллютантам относятся нефтя- ные, полициклические ароматические, галогенированые углеводороды, пестициды, растворители, тяжелые металлы и их соли. Попадая во внешнюю среду, 